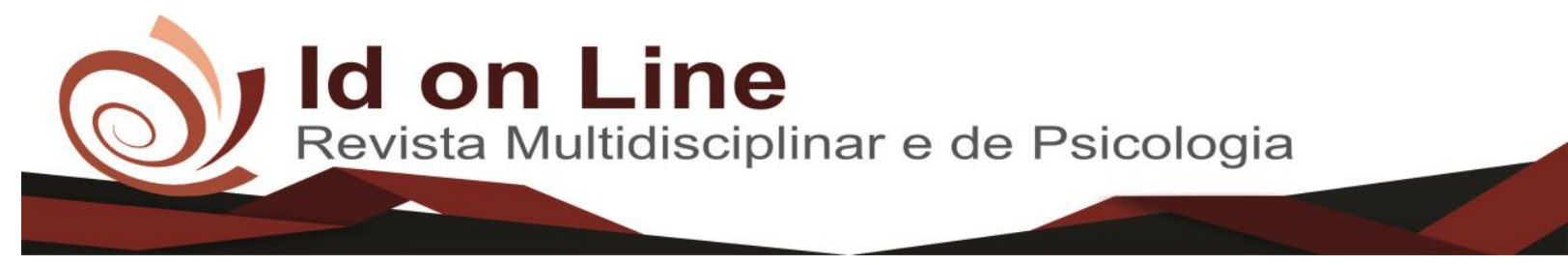

Artigo

\title{
Balanceamento do número de Sílabas e Haplologia atuando no processo do Portmanteau
}

\author{
Emerson Viana Braga'; Vera Pacheco ${ }^{2}$
}

\begin{abstract}
Resumo: O presente trabalho tem como objetivo analisar a formação de palavras pela sobreposição de duas bases, conhecida como portmanteau, bem como a aplicação do fenômeno fonológico da haplologia nessa junção das bases, sob a hipótese de uma atuação do balanceamento de sílabas entre essas bases. Utilizamos a teoria morfofonológica item e arranjo que consiste na análise dos constituintes da palavra formada. Por meio das análises, há uma tendência de eliminação de sílaba, na formação de palavras por portmanteau, para haver uma balanceamento do número de sílabas das bases envolvidas na nova palavra formada, como pode-se verificar na palavra chafé, combinação de chá + café. A eliminação da sílaba [ka] da base café, tornando-a monossílaba como a outra base envolvida no processo chá, ocasiona um balanceamento do número de sílabas das bases formadoras de novas palavras, ou seja, ambas ficam com uma sílaba. Evidencia-se, portanto, que regras fonológicas de balanceamento de número de sílabas e haplologia ocorrem nos processos de formação de palavras como o portmanteau.
\end{abstract}

Palavras-chave: Portmanteau; Balanceamento de sílabas; Haplologia.

\section{Balancing the Number of Syllables and Haplology Acting in the Portmanteau Process}

\begin{abstract}
The present work aims to analyze the formation of words by the overlapping of two bases, known as portmanteau, as well as the application of the phonological phenomenon of haplology in this junction of the bases, under the hypothesis of a syllable balancing act between these bases. We use the morphophonological theory item and arrangement that consists of the analysis of the constituents of the word formed. Through the analyzes, there is a tendency to eliminate syllables, in the formation of words by portmanteau, to have a balance of the number of syllables of the bases involved in the new word formed, as can be seen in the word chafé, (chá + café) combination. The elimination of the syllable [ka] from the café base, making it monosyllable as the other base involved in the chá process, causes a balancing of the number of syllables of the bases forming new words, that is, both are with one syllable. It is evident, therefore, that phonological rules of number-syllable balancing and haplology occur in the processes of word formation like the portmanteau.
\end{abstract}

Keywords: Portmanteau; Syllabic balancing; Haplology.

\footnotetext{
${ }^{1}$ Mestrando em Linguística pela Universidade Estadual do Sudoeste da Bahia - PPGLIN/UESB e bolsista CAPES. Possui graduação em Letras Vernáculas também pela UESB. E-mail: emevibra@ @otmail.com.

${ }^{2}$ Professora Plena da graduação e pós-graduação na Universidade Estadual do Sudoeste da Bahia - UESB. Possui graduação em Linguística pela Universidade Estadual de Campinas, mestrado e doutorado em Linguística pela mesma universidade. E-mail: vera.pacheco@gmail.com.
} 


\section{Introdução}

Entre os processos de formação de palavras existe a operação morfológica do portmanteau (PIÑEROS, 2000, 2002; ARAÚJO, 2000), processo este, que sobrepõe duas bases com perda de material fonético (*namoradomarido>>namorido). Além disso, é possível observar a ocorrência da haplologia - supressão uma sílaba em fronteira de palavra - no processo morfológico. A ocorrência do fenômeno fonológico no processo morfológico denota que é comum a ocorrência de processos fonológicos em operações morfológicas de formação de palavra (*sacopicolé>> *saeecolé>>sacolé).

Diante disso, questionamos: qual o princípio subjacente nas formações do portmanteau? Nossa hipótese é de que, a princípio, o que rege esse tipo de formação é o balanceamento de sílabas. Nesse sentido, nosso objetivo é avaliar os portmateaux do Português Brasileiro, olhando para o número de sílabas das bases antes e depois da sobreposição dessas bases.

Defendemos, portanto, que, nessa sobreposição de bases, há uma regra para balanceamento do número de sílabas entre as duas bases envolvidas, ainda que haja a ocorrência da haplologia. Para isso, levamos em consideração que o fenômeno fonológico apresente duas naturezas, a saber: apagamento (desparecimento total de uma das sílabas) ou por degeminação (desparecimento parcial)

No decorrer do texto, serão apresentados os processos. Em seguida, apresentaremos a maneira como essas bases se comportam nessa junção e, por fim, traremos uma justificativa para essa regra do balanceamento do número de sílabas entre as bases, nos assegurando a partir da natureza da haplologia (degeminação ou apagamento).

\section{Justaposição, portmanteau e haplologia: processos envolvidos}

Em qualquer língua natural é comum a criação de novas palavras a partir de operações morfológicas à semelhança do processo da justaposição e o do portmanteau. Na justaposição não há queda de segmentos das bases, além disso, há a conservação do acento a constitui, como em mata-borrão. Enquanto no portmanteau há sobreposição de duas bases, formando uma palavra morfológica, como em chafé (chá + café). Sendo assim, o portmanteau se difere da justaposição porque não se verifica a preservação de todos os segmentos das bases originais. A 
recorrência desses processos é observada, com maior frequência, em situações comunicativas informais.

\section{O portmanteau}

Villalva (2007) considera o portmanteau ${ }^{3}$ como justaposição resultante do processo da amalgamação, em que uma base junta-se a outra base "numa combinação aleatória de segmentos" (VILLALVA, 2007, p. 47) como pode ser observado em (1)
(1) fidalgo
filho + de + algo (VILLALVA, 2007, p. 47)

Villalva (2007) apresenta também diferentes séries de outras combinações que são possíveis e que são plenamente agregadas no português: como em 2a, bem como em outras línguas, como o inglês $2 \mathrm{~b}$, palavras que são percebidas por meio de neologismos que, segundo ela, são "mais ou menos familiares e mais ou menos efémeros" (VILLALVA, 2007, p. 47), em 3, outras que podem ser utilizadas para nome de empresas, em 4, palavras que são recursos bastante usados por autores da literatura e Villalva (2007) retoma alguns exemplos que extraiu das obras de Cesariny, Sena e Mia Couto, visto em 5, e de formas que podem gerar amálgamas advindos de empréstimos de outras línguas, sobretudo do Latim, como em 6:

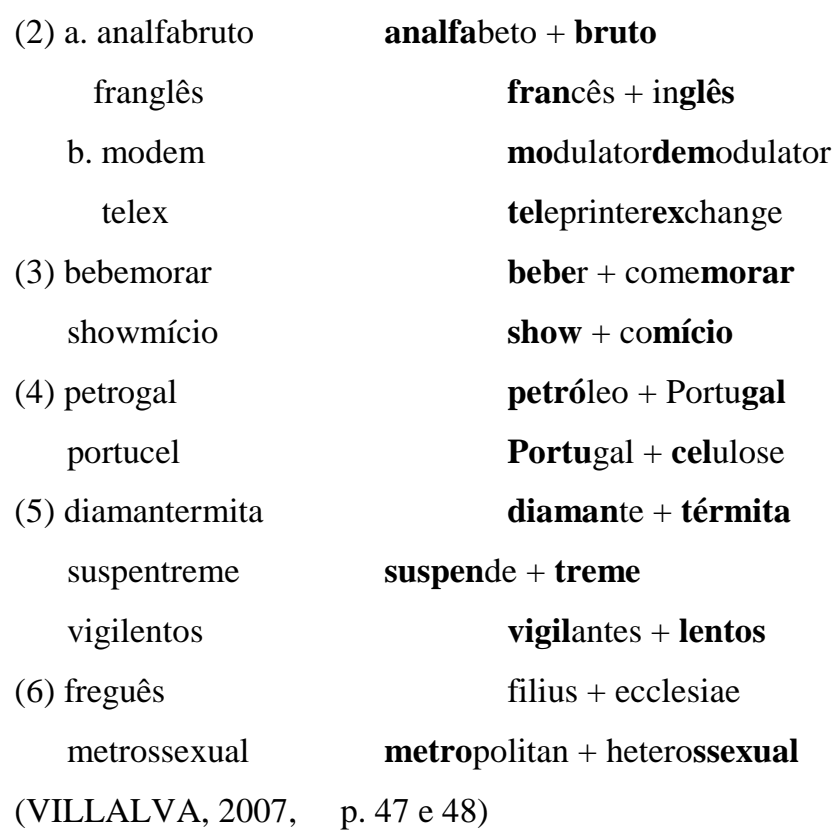

${ }^{3}$ Villalva (2007) usa o termo justaposição para os processos de composição com perda de material fonético. 
Por outro lado, Araújo (2000) apresenta o portmanteau como um "processo de formação de palavras por composição" (ARAÚJO, 2000, p. 5), sendo resultante do processo de amálgama entre duas formas existentes numa nova com "dois significados embrulhados em uma só palavra" (ARAÚJO, 2000, p. 5), como pode ser visto em (7):

(7) vampeta vampiro + capeta (ARAÚJO, 2000, p. 6)

Como pode ser observado em (7), a palavra é sobreposta ou concatenada (ocorre também em 1, 2, 3, 4, 5 e 6) e perde, segundo Araújo (2000), eventualmente, material segmental (elementos fonológicos ou silábicos), o que propicia a formação de uma nova palavra. Além disso, ele argumenta que essas palavras podem manter "as características prosódicas dos elementos componentes à direita ou à esquerda" (ARAÚJO, 2000, p. 6).

\section{O fenômeno da haplologia}

A haplologia, segundo Gonçalves e Silva (2006), caracteriza-se pela queda de sílaba em fronteira de morfemas ou de palavras. Logo, torna-se um típico fenômeno da interface da Fonologia: ou com a Morfologia ou com a Sintaxe. Percebe-se a ocorrência da haplologia quando sílabas apresentam, em fronteira, identidade, como em 8:

(8) Faculdade de letras >Faculda[de]letras (GONÇALVES; SILVA, 2006, p. 1)

Observa-se que a haplologia ocorre no encontro das duas palavras, formando um sintagma, uma vez que houve supressão da última sílaba da palavra anterior, devido à semelhança que há com a sílaba inicial da palavra seguinte (no caso, do exemplo, de uma preposição). Em 8, temos um exemplo de haplologia sintática, assim como em cal[do]de cana'. O fenômeno ocorre também no interior do vocábulo, sendo assim, uma mudança linguística que consiste na supressão de uma de duas sílabas iguais ou semelhantes, contíguas, como idolatria por idololatria (HOUAISS, 2009, p. 1005). 
Nesse caso, Camara Jr. (1986) apresenta também uma boa definição para a haplologia, em fronteira de morfema: um processo morfofonêmico que advém da composição ou derivação e que consiste na supressão de uma sílaba, sobretudo entre duas sílabas iguais e contíguas. Gonçalves e Silva (2006) dizem que, no âmbito da Morfologia, a ocorrência de haplologia não é tão recorrente, quanto na Sintaxe.

Porém, é possível perceber um número significativo do processo numa formação de base+base, parecidos com os dos exemplos em 9:

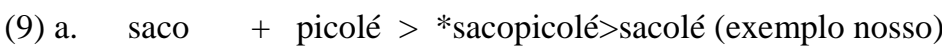

b. trágico + cômico $>$ *tragicocomico> tragicômico (CRYSTAL, 2000, p. 137)

É possível observar de imediato a contiguidade da sílaba [ko], no segundo exemplo. No primeiro, temos primeiro a eliminação de uma sílaba na base da direita. Tais exemplos configuram-se como haplologia morfológica. Eles são a prova de que a supressão das sílabas é acurada pela interação dos componentes fonológico e morfológico, uma vez que revelam formação de palavra por justaposição amalgamada com queda de segmentos idênticos.

\section{Metodologia}

Como forma de compreender a ocorrência da haplologia no processo do portmanteau, constituímos um corpus por meio da coleta de palavras compostas já consagradas na língua e na literatura, além de dicionários online e palavras que apareceram, atualmente, no Português Brasileiro em situações de informalidade. ${ }^{4}$

Inicialmente, olhamos palavras justapostas, pois se trata de um tipo de composição que une duas bases para a formação de uma nova palavra. A seguir, analisamos os portmanteaux que também englobam a junção de duas bases, no entanto, essas bases sofrem queda de sílaba.

Dividimos a análise, portanto, em três partes, observando o comportamento das bases nas formas resultantes, a saber: a justaposição; o portmanteau, um processo que envolve a

\footnotetext{
${ }^{4}$ Para compor o corpus da análise, além de palavras retiradas de gramáticas, dicionários online e contextos comunicativos diversos, recorremos também a algumas palavras encontradas em alguns trabalhos, tais quais Gonçalves (2004) e Andrade e Rondinini (2016), pois essas palavras são de contextos específicos.
} 
sobreposição de bases, o que denota a queda de sílaba; e o portmanteau com queda de sílaba, abrindo campo para a ocorrência da haplologia.

\section{Resultados e discussões}

\section{Compostos formados com manutenção do material fonético das bases: a justaposição}

Como já apresentado, no processo por justaposição, há preservação fonética das bases, mantendo-se na palavra formada o acento e todos os segmentos das palavras primitivas, como em mata-borrão, guarda-roupa e girassol. Andrade e Rondinini (2016, p. 866) discutem que "são preservadas a estrutura e a pauta acentual das bases combinadas, resultando em duas palavras prosódicas e uma morfológica".

Assim, na justaposição, as bases são mantidas inalteradas com a mesma quantidade de sílabas, a mesma pauta acentual, como pode ser observado, no quadro 01

Quadro 01: Esquema representacional de palavras por justaposição com número igual de sílabas entre as bases.

\begin{tabular}{|c|c|c|c|}
\hline Base esquerda & $\begin{array}{c}\text { Base } \\
\text { direita }\end{array}$ & $\begin{array}{c}\text { Bases } \\
\text { justapostas }\end{array}$ & $\begin{array}{l}\text { Número de sílabas das } \\
\text { bases }\end{array}$ \\
\hline a. cavalo & marinho & cavalo-marinho & $\begin{array}{l}\text { ca.va.lo . ma.ri.nho } \\
\begin{array}{llllll}1 & 2 & 3 & 1 & 2 & 3\end{array}\end{array}$ \\
\hline b. guarda & chuva & guarda-chuva & \begin{tabular}{cccc}
\multicolumn{3}{c}{ guar.da } & chu.va \\
1 & 2 & 1 & 2 \\
\end{tabular} \\
\hline c. passa & tempo & passatempo & \begin{tabular}{llll} 
& \multicolumn{3}{c}{ pas.sa .tem.po } \\
1 & 2 & 1 & 2
\end{tabular} \\
\hline d. guarda & roupa & guarda-roupa & $\begin{array}{c}\text { guar.da } \text {. rou.pa } \\
1212\end{array}$ \\
\hline e. vai & vem & vaivém & \begin{tabular}{cc}
\multicolumn{2}{l}{ vai .vem } \\
$1 \quad 2$
\end{tabular} \\
\hline
\end{tabular}

Como se pode observar no quadro 01, as bases primitivas envolvidas na composição possuem o mesmo número de sílabas. Em (a), tem-se duas bases trissílabas; em (b, c e d) são duas bases dissílabas; e em (e) duas bases monossílabas. 
Apesar de se encontrar no Português alguns compostos formados por bases com número diferentes, à semelhança de cachorro-quente; amor-perfeito e peixe-espada ${ }^{5}$, esses casos são em menor quantidade do que os casos em que as bases possuem número de sílaba igual.

Ainda é possível encontrar compostos cujas bases possuem número de sílaba diferente quando uma das bases é monossílabo, conforme mostra o quadro 02

Quadro 02: Esquema representacional de palavras por justaposição com número diferente de sílabas entre as bases.

\begin{tabular}{|c|c|c|c|}
\hline Base esquerda & $\begin{array}{c}\text { Base } \\
\text { direita }\end{array}$ & $\begin{array}{c}\text { Bases } \\
\text { justapostas }\end{array}$ & $\begin{array}{l}\text { Número de sílabas das } \\
\text { bases }\end{array}$ \\
\hline a. bumba & boi & bumba-boi & 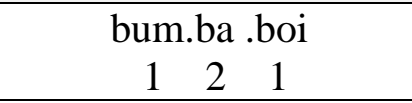 \\
\hline b. couve & flor & couve-flor & $\begin{array}{c}\text { cou.ve flor } \\
1 \quad 2 \quad 1\end{array}$ \\
\hline c. ponta & pé & pontapé & $\begin{array}{l}\text { pon.ta .pé } \\
\begin{array}{ccc}1 & 2 & 1 \\
\end{array}\end{array}$ \\
\hline d. verde & mar & verde-mar & $\begin{array}{l}\text { ver.de .mar } \\
121\end{array}$ \\
\hline
\end{tabular}

Vemos, no quadro 02, que as bases não apresentam o mesmo número de sílabas, no entanto, ainda mantêm todo seu material fonético. Portanto, para haver a justaposição não pode ter queda de sílaba.

A tendência que a língua tem de formar compostos com bases que compartilham o mesmo número de sílaba, sem redução de material fonético, pode ser uma evidência considerável para a hipótese de que na formação de compostos um critério que deva ser considerado é o balanceamento de sílabas das bases, ou seja, no composto formado a base da esquerda e da direita tendem a ter o mesmo número de sílaba.

\section{Compostos formados com perda de material fonético das bases: o portmanteau}

Nem sempre, as formações de palavras seguem o padrão de justaposição. Há situações em que tem eliminação de sílabas como mostra o quadro 03

\footnotetext{
${ }^{5}$ A rigor, há uma diferença semântica entre os compostos por justaposição formados por bases com número de sílaba igual e diferente. Considerando, contudo, que esse não é o escopo do presente trabalho, essa discussão não será desenvolvida aqui.
} 
Quadro 03: Esquema representacional portmanteau formado por base monossílaba + bases dissílaba.

\begin{tabular}{|c|c|c|c|c|}
\hline $\begin{array}{c}\text { Base } \\
\text { esquerda }\end{array}$ & $\begin{array}{c}\text { Base } \\
\text { direita }\end{array}$ & $\begin{array}{c}\text { Queda } \\
\text { de sílaba }\end{array}$ & Portmanteau & $\begin{array}{c}\text { Balanceamento de } \\
\text { sílabas }\end{array}$ \\
\hline Chá & Café & $\begin{array}{c}* \text { chacafé } \\
>\text { chafé }\end{array}$ & Chafé & $\begin{array}{c}\text { chá .fé } \\
1\end{array}$ \\
\hline
\end{tabular}

Na língua, também é muito comum a junção de duas bases com queda de sílaba ou sílabas. Essas bases, ao se sobreporem, caracterizam-se como portmanteau, fenômeno morfológico, apresentando no início deste artigo, que é resultado de uma nova palavra a partir da sobreposição de duas bases com casual perda de material fonético, como no exemplo do quadro 03 com a palavra chafé (chá + café), termo usado para descrever um café considerado fraco.

Com a queda da sílaba [ka] da base da direita, ocorre uma cadência maior entre as bases para manutenção rítmica do português. A justificativa se dá pela facilidade em marcar sílabas tônicas e átonas mais à esquerda do que à direita. A queda da sílaba [ka], portanto, permite que o padrão rítmico da língua mantenha uma melhor cadência, pois, como assegura Bisol (2000), palavras em pés silábicos tendem a manter o pé métrico mais à cabeça de esquerda. Portanto, permite-se afirmar porque os exemplos no quadro 01 mantêm bases à esquerda maiores que às da direita.

Desse modo, fica claro que quando há manutenção de todo material fonético das bases, na formação de uma nova palavra, o processo envolvido é o da justaposição. Por outro lado, quando i- a primeira base monossílaba encontra uma segunda base dissílaba e ii- duas bases diferentes se encontram (quadro 04, a seguir), ocorre eliminação.

Por meio dos exemplos dos quadros 03 e 04, é possível identificar um balanceamento de sílabas entre as bases. Esse balanceamento ocorre, justamente, porque há perda de sílaba(s) para manter um equilíbrio entre as bases, qual seja, as bases passam a ter número de sílaba igual.

Nessa perspectiva, são em formações de palavras por portmanteau, onde há uma tendência de eliminação de sílaba para haver um balanceamento do número de sílabas das bases envolvidas na forma resultante da sobreposição dessas bases, como vista no quadro 04 
Quadro 04: Esquema representacional de balanceamento entre as bases do portmanteau.

\begin{tabular}{|c|c|c|c|c|}
\hline $\begin{array}{c}\text { Base } \\
\text { esquerda } \\
\end{array}$ & $\begin{array}{c}\text { Base } \\
\text { direita } \\
\end{array}$ & Queda de sílaba(s) & $\begin{array}{l}\text { Aplicação do } \\
\text { portmanteau }\end{array}$ & $\begin{array}{c}\text { Balanceamento } \\
\text { de sílabas }\end{array}$ \\
\hline a. Namorado & Marido & $\begin{array}{c}\text { *namoradomarido }> \\
\text { namorido }\end{array}$ & Namorido & $\begin{array}{cccc}\text { na.mo } & \text { ri.do } \\
1 & 2 & 1 & 2\end{array}$ \\
\hline b. Vagabunda & Piranha & $\begin{array}{c}\text { *vagabundapiranha } \\
\text { >vagaranha }\end{array}$ & Vagaranha & $\begin{array}{l}\text { va.ga } \text {.ra.nha } \\
\begin{array}{llll}1 & 2 & 1 & 2 \\
\end{array}\end{array}$ \\
\hline c. Bolsonaro & Lixo & $\begin{array}{c}* \text { Bolsonarolixo }>\text { Bol } \\
\text { solixo }\end{array}$ & Bolsolixo & 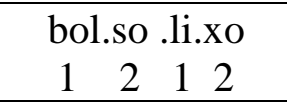 \\
\hline d. Prostituta & Puta & $\begin{array}{c}\text { *prostitutaputa>pros } \\
\text { tiputa }\end{array}$ & Prostiputa & $\begin{array}{l}\text { pro.ti .pu.ta } \\
\begin{array}{llll}1 & 2 & 1 & 2\end{array}\end{array}$ \\
\hline
\end{tabular}

Em (04a e b), o balanceamento de sílaba acontece com bases de estruturas parecidas, em que as bases da esquerda são polissílabas e as da direita trissílabas. Com isso, caem duas sílabas das primeiras bases e apenas uma da segunda, possibilitando, na forma resultante, que ambas as bases fiquem com duas sílabas. Em (04c e d), a primeira base também é polissílaba. Por outro lado, diferentemente, de (04a, b), a segunda base já é dissílaba. Logo, duas sílabas da primeira base caem para que haja um balanceamento de sílaba e a forma resultante seja composta por duas bases dissílabas.

O resultado, do quadro 04, portanto, é tido por meio de um balanceamento do número de sílabas das bases formadoras de novas palavras, a saber: ambas com duas sílabas.

Ainda, há situações em que essa eliminação pode propiciar a ocorrência da haplologia. No processo do portmanteau, como já foi visto, há uma tendência de eliminação de sílaba para que ambas as bases tenham o mesmo número de sílabas. É possível, ainda, que essa eliminação resulte na sequência de segmentos idênticos. Logo, uma novo desaparecimento é observado entre sílabas contíguas, no nível fonético. Esse desaparecimento de sílabas contíguas semelhantes é caracterizada como haplologia e sua natureza será regida pela manutenção do balanceamento de sílabas entre as bases.

Sendo assim, a haplologia pode ser acionada, ou não, no processo do portmanteau e este precisa ser regido pelo balanceamento de sílaba(s) entre as bases. No entanto, o fenômeno fonológico pode se manifestar em palavras que, com a queda de uma sílaba, mantenham o mesmo número de sílabas entre as bases, como em sacolé (saco + picolé), em que a queda sílaba [pi] da segunda base promove o balanceamento e, seguida, duas sílabas contíguas são idênticas [co], bem como em palavras com bases de números distintos, como em borboletras (borboleta + letras), em que a queda da sílaba [ta] da primeira base não permitiria um equilíbrio entre as 
bases, ainda que as sílabas contíguas ([le] refletem na ocorrência da haplologia. Nesse sentido, qual a natureza da haplologia está envolvida no pormanteau? Degeminação ou apagamento?

Propomos uma abordagem da haplologia que discorra sobre ambas naturezas. No quadro 06 apresentamos um esquema representacional que descreve a haplologia com característica de degeminação

\begin{tabular}{|c|c|c|c|c|c|}
\hline $\begin{array}{c}\text { Base } \\
\text { esquerda }\end{array}$ & $\begin{array}{c}\text { Base } \\
\text { direita }\end{array}$ & $\begin{array}{c}\text { Eliminação de } \\
\text { sílaba }\end{array}$ & Degeminação & $\begin{array}{c}\text { Aplicação } \\
\text { do } \\
\text { portmanteau } \\
\text { e da } \\
\text { haplologia } \\
\end{array}$ & $\begin{array}{c}\text { Balanceamento } \\
\text { de sílabas }\end{array}$ \\
\hline a. Saco & Picolé & $\begin{array}{c}*_{\text {sacopicolé> }} \\
\text { *sacocolé }^{\text {sacol }}\end{array}$ & $\begin{array}{c}\text { *sacocolé>sa } \\
\text { colé }\end{array}$ & sacolé & $\begin{array}{l}\text { sa.co .lé } \\
1212 \\
\end{array}$ \\
\hline b. Chato & $\begin{array}{c}\text { Mattos } \\
\text { o }\end{array}$ & $\begin{array}{c}* \text { chatomattoso } \\
>*_{\text {chatottoso }}\end{array}$ & $\begin{array}{c}* \text { chatottoso }> \\
\text { chattoso }\end{array}$ & chattoso & $\begin{array}{ccc}\text { cha } \text {.tto } & \text { so } \\
1 & 21 & 2\end{array}$ \\
\hline c. Trágico & Cômico & $X$ & $\begin{array}{c}\text { *trágicocômi } \\
\text { co> } \\
\text { tragicômico }\end{array}$ & $\begin{array}{c}\text { Tragicômic } \\
\text { o }\end{array}$ & $\begin{array}{l}\text { tra.gi .co } \\
\begin{array}{llllll}1 & 2 & 31 & 2 & 3\end{array}\end{array}$ \\
\hline
\end{tabular}

Nos exemplos do quadro 05, temos o desaparecimento de uma sílaba para a manutenção de balanceamento de sílabas entre as bases, [pi], em (a) e [ma] em (b). Essa eliminação resulta em duas bases dissílabas, saco+cole e chato+ttoso resultando, ao mesmo tempo, sequência de segmentos idênticos [ko] e [to], para a primeira formação e para a segunda, respectivamente, contexto propício para a ocorrência da haplologia, uma vez que tal fenômeno trata de queda de sílaba semelhante ou idêntica em fronteira de morfema. No exemplo (c) a aplicação da haplologia acontece no contato direto entre as bases.

A natureza da haplologia envolvida nos exemplos do quadro 05 é de degeminação (exemplo: saco + colé). As sílabas em negrito fundem-se no nível fonético, pois, por haver sobreposição das bases, caracterizam-se como portmanteaux e este processo, como visto anteriormente, é regido pelo balanceamento de sílaba(s) entre as bases. Sendo assim, não seria possível dizer que ocorre apagamento, uma vez que, caso uma das bases perdessem uma das sílabas contíguas, haveria um desequilíbrio entre as sílabas. Além do mais, no exemplo (c), essa fusão denota que há perda de material fonético, ainda que fundido, e, assim, reitera sua característica como portmanteau e não como justaposição. 
Por outro lado, há alguns portmanteaux que apresentam a aplicação da haplologia com natureza de apagamento, conforme mostra o quadro 06

Quadro 06: Esquema representacional com ocorrência da haplologia com natureza de apagamento no processo do portmanteau.

\begin{tabular}{|c|c|c|c|c|c|}
\hline $\begin{array}{c}\text { Base } \\
\text { esquerda }\end{array}$ & $\begin{array}{c}\text { Base } \\
\text { direita }\end{array}$ & $\begin{array}{l}\text { Eliminação } \\
\text { de sílaba }\end{array}$ & Apagamento & $\begin{array}{c}\text { Aplicação } \\
\text { do } \\
\text { pormanteau } \\
\text { e da } \\
\text { haplologia }\end{array}$ & $\begin{array}{c}\text { Balanceamento } \\
\text { de sílabas }\end{array}$ \\
\hline a. Borboleta & Letras & $\begin{array}{l}\text { *borboletalet } \\
\text { ras> } \\
\text { *borboleletra } \\
\text { s }\end{array}$ & $\begin{array}{l}\text { *borboleletras } \\
\text { >borboletras }\end{array}$ & Borboletras & $\begin{array}{l}\text { Bor.bo. le.tras } \\
\begin{array}{llll}1 & 2 & 1 & 2\end{array}\end{array}$ \\
\hline b. Advogada & Gata & $\begin{array}{c}\text { *advogadaga } \\
\text { ta }> \\
\text { *advogagata }\end{array}$ & $\begin{array}{c}\text { *advogagata }>a \\
\text { dvogata }\end{array}$ & Advogata & $\begin{array}{llll}\text { Ad.vo. ga } & \text { ta } \\
1 & 2 & 1 & 2\end{array}$ \\
\hline c. Mendiga & Gata & $\mathrm{X}$ & $\begin{array}{c}* \text { mendigagata } \\
>\text { mendigata }\end{array}$ & Mendigata & \begin{tabular}{llll} 
& \multicolumn{3}{c}{ Men.di .ga.$t a$} \\
1 & 2 & 1 & 2 \\
\end{tabular} \\
\hline d. Promoção & $\begin{array}{l}\text { Mochil } \\
\text { a }\end{array}$ & $\begin{array}{l}\text { *promoçãom } \\
\text { ochila> } \\
\text { *promomoch } \\
\text { ila }\end{array}$ & $\begin{array}{l}\text { *promomochil } \\
\text { a>promochila }\end{array}$ & Promochila & $\begin{array}{cccc}\text { Pro.mo } & \text { chi.la } \\
1 & 2 & 1 & 2\end{array}$ \\
\hline
\end{tabular}

Até aqui, discutimos que, em formação de palavras com queda de material fonético, as bases tendem a manter um balanceamento de sílabas entre si. Nos exemplos do quadro 06, trabalhar com a hipótese de que esteja havendo degeminação das sílabas é assumir que as bases vão apresentar número de sílabas diferentes, havendo um desequilíbrio de número de sílabas entre elas. Ao que nos parece, que nos dados do quadro 06, a haplologia funciona como queda das sílabas, pois, em (a) e (b) com a queda das sílabas [ta] e [da], a aplicação da haplologia resultaria em borbo(le)tras e advo(ga)ta, deixando as bases da esquerda com duas sílabas e as da direita com duas.

O contrário acontece no exemplo (d), pro(mo)chila, em que base da esquerda perde a sílaba [sãw] e as sílabas contíguas seguintes [mo] são iguais, configurando-se como haplologia. Desse modo, a base da direita fica com maior número de sílabas que a da esquerda (promo(mo)chila). Nesse caso, portanto, há a queda da sílaba [mo] da base da direita para equilibrar o número de sílabas entre as bases e a forma resultante será promo(mø)chila. Em (c), não há eliminação de sílaba, pois a haplologia já ocorre diretamente com o contato das sílabas contíguas, porém o desequilíbrio permanece, mendi(ga)gata. A ocorrência da haplologia, nesse 
caso, também, é através da queda, resultando na forma mendi(ga)gata (ambas as bases ficam dissílabas).

A natureza da haplologia, nestes casos, portanto, se aplica como apagamento, não como degeminação, para se alcançar balanceamento de número de sílabas entre as bases. Em borbo(lele)tras, por exemplo, a sílaba da base da esquerda precisa ser apagada para que haja balanceamento entre as bases em sua forma resultante (base b $_{1}$ borbo + base $_{2}$ : letras $=$ borboletras).

Fica explícito, portanto, pelos exemplos de portmanteaux que, de fato, o que prevalecerá é o balanceamento de sílabas entre as bases.E com o acionamento da haplologia, bem como seu tipo de natureza (degeminação ou apagamento), é possível confirmar essa hipótese com mais nitidez.

É possível observar, ainda, que os exemplos dos quadros 05 e 06 permitem um melhor padrão rítmico com o desaparecimento de segmentos semelhantes ou idênticos, seja de natureza de degeminação ou de apagamento. E, além de promover um equilíbrio entre as bases envolvidas, também, concorrem para a eurritmia.

\section{Considerações finais}

Neste artigo, analisamos que a perda segmental está relacionada com a haplologia, quando elimina segmentos contíguos semelhantes e a perda de sílaba ou sílabas está relacionada com o balanceamento do número de sílabas das bases da palavra formada. Fica claro que regras fonológicas de balanceamento de número de sílabas e haplologia estão atuando no portmanteau.

No que tange ao acionamento da haplologia, mostramos que o que irá prevalecer, ainda, é o balanceamento do número de sílabas entre as bases. Logo, no fenômeno fonológico pode ser visto um desaparecimento que pode ser de natureza de degeminação ou de apagamento. $\mathrm{O}$ tipo de natureza só pode ser confirmado quando se leva em consideração o equilíbrio entre as bases envolvidas no contexto.

\section{Referências}

ANDRADE, K. E.; RONDININI, R. B. Cruzamento vocabular: um subtipo da composição? DELTA. Documentação de Estudos em Linguística Teórica e Aplicada (Online), v. 32, p. 861887, 2016. 
ARAÚJO, G. A. Morfologia não-concatenativa em português: os portmanteaux. Caderno de Estudos linguísticos: Campinas, (39): 5-21, 2000.

BISOL, Leda. O troqueu silábico no sistema fonológico (um adendo ao artigo de Plínio Barbosa). Delta, São Paulo, v. 16 (2), p. 403-413, 2000.

CÂMARA JR, J. M. Dicionário de lingüística e gramática. $13^{\mathrm{a}}$ ed. Rio de Janeiro: Vozes, 1986.

CRYSTAL, D. Dicionário de linguística e fonética. Tradução e adaptação [da $2^{\mathrm{a}}$ ed. Inglesa ver. e ampliada, publicada em 1985]. DIAS, Maria Carmelita Pádua. Rio de Janeiro: Jorge Zahar Ed., 2000.

GONÇALVES, Carlos Alexandre. Processos Morfológicos não-concatenativos do português brasileiro: formato morfoprosódico e latitude funcional. Alfa (ILCSE/UNESP): São Paulo. 48(1): 9-28, 2004.

GONÇALVES, C. A. V.; SILVA, L. A. Haplologia morfológica das formas X-ção: enfoque diacrônico e representação morfo-prosódica. Caderno Seminal Digital: Rio de Janeiro, v. 6, p. 148-164, 2006.

HOUAISS, A.; VILLAR, M. de S. Dicionário de Houaiss da Língua Portuguesa. $1^{\text {a }}$ ed. Rio de Janeiro: Objetiva, 2009.

PIÑEROS, C. E. Word-blending as a case of non-concatenative morphology in Spanish. Rutgers Optmality Aechive, 2000. Disponível em<roa.rutgers.edu/files/343-0999/343PINEROS-0-O.PDF> Acesso em 01 de mai. de 2018.

. The creation of portmanteau in the extragrammatical morphology of Spanish. Rutgers Optimality Archive, 2002. Disponível em: <http://roa.rutgers.edu/files/5260602/526-0602-PINEROS-0-0.PDF> Acesso em 01 de mai. de 2018.

VILLALVA, A. Morfologia do português. Lisboa: Universidade Aberta, 2007.

Como citar este artigo (Formato ABNT):

BRAGA, Emerson Viana; PACHECO, Vera. Balanceamento do número de Sílabas e Haplologia atuando no processo do Portmanteau. Id on Line Rev.Mult. Psic., 2019, vol.13, n.43, p. 1108-1120. ISSN: 1981-1179. 